\title{
Double- versus single-balloon catheters for labour induction and cervical ripening: a meta-analysis
}

\author{
Xiyao $\mathrm{Liu}^{1 \dagger}$, Yu Wang ${ }^{2 \dagger}$, Fan Zhang ${ }^{3}$, Xiaoni Zhong ${ }^{3}$, Rong Ou ${ }^{3}$, Xin Luo ${ }^{1 *}$ and Hongbo Qi ${ }^{*}$
}

\begin{abstract}
Background: The induction of labour is an increasingly common procedure in the obstetrics field. Various methods have been used to induce labour, among which balloon catheters play an important role. Whether the specifically designed double-balloon catheter is better than the single-balloon device in terms of efficacy, efficiency, safety and patient satisfaction remains controversial. Identifying even small differences between these two devices could be useful to guide clinical practices, to further explore their mechanisms, and to promote a better understanding of the optimal methods for inducing labour.

Methods: Using the population, intervention, comparison, outcomes and study designs (PICOS) principle, we searched the PubMed, EMBASE, OVID, SCI, CENTRAL, ClinicalTrial.gov, and CDSR databases to identify relevant randomised controlled trials (RCTs) from inception through February 14, 2018. The primary outcome was the caesarean delivery rate, and the secondary outcomes focused on efficacy, efficiency, safety, and patient satisfaction. The relative risks or mean differences, including their $95 \%$ confidence intervals, were calculated using fixed-effects or random-effects models. All statistical analyses were completed with RevMan version 5.3.
\end{abstract}

Results: From a total of 1326 articles, 7 RCTs involving 1159 women were included. There were no significant differences in primary outcomes (RR, $0.88[0.65,1.2]$; $p$-value, 0.43$)$ or secondary outcomes identified between single- and double-balloon catheters. However, heterogeneity existed for some aspects.

Conclusion: Both kinds of balloon catheter have similar levels of efficacy, efficiency, safety and patient satisfaction; however, the single-balloon method is considered to be more cost-effective.

Keywords: Labour induction, Cervical ripening, Balloon catheter, Meta-analysis

\section{Background}

Labour induction refers to the process of artificially stimulating the uterus to begin labour [1], which is an increasingly common procedure. Cervical status, measured by the Bishop score [2], is a good predictor for the outcome of labour induction. If the cervix is unfavourable, no method is highly successful, and a ripening process is generally employed to obtain cervical effacement and dilatation prior to induction [3-5]. Methods used for cervical ripening can be broadly divided into mechanical devices and

\footnotetext{
*Correspondence: 14802315@qq.com; qihongbocy@gmail.com

${ }^{+}$Xiyao Liu and Yu Wang contributed equally to this work.

'Department of Obstetrics and Gynecology, The First Affiliated Hospital of

Chongqing Medical University, No. 1 Youyi Road, Yuzhong District,

Chongqing 400016, China

Full list of author information is available at the end of the article
}

pharmacologic options [6, 7]. Compared with pharmacologic agents, mechanical methods, which were the first methods developed to ripen the cervix or induce labour [8], have similar levels of effectiveness but incur fewer episodes of adverse events (such as uterine tachysystole), have lower costs and are easier to preserve [6].

The balloon catheter, including both double- and single-balloon catheters, appears to be a widely accepted mechanical method and is recommended by the WHO for the induction process [9]. The original version of the Foley (single-balloon) catheter was initially described by Barnes in 1863 but was not described again until 1967, by Embrey and Mollison [10]. In 1991, Atad described the first double-balloon variation [11]. The Cook Cervical Ripening Balloon 
(CCRB), which uses an identical mechanism to that of the Atad catheter, was approved by the United States Food and Drug Administration (USFDA) in 2013 [12]. Only the double-balloon catheter (either Atad or Cook) is specifically designed and licensed for labour induction, while the Foley catheter is used beyond instructions.

Mechanical ripening devices apply pressure to the internal face of the cervix, directly overstretching the lower uterine segment and indirectly increasing the localised secretion of prostaglandin [13]. In addition to the local effect, mechanisms that involve neuroendocrine reflexes (such as the Ferguson reflex) may promote the onset of contractions [14]. Purportedly, the double-balloon (either Atad or Cook) option has an additional cervico-vaginal balloon, which applies greater pressure to both sides of the cervix and avoids the need for traction [11].

Given the increasing induction rate, the knowledge of even small differences between methods could be useful, not only to guide clinical practices but also to further explore the mechanism underlying the mechanical induction of labour and may promote a better understanding of the optimal methods for labour induction. However, studies examining the superiority of the double-balloon catheter reveal mixed results [15-23]. We conducted this metaanalysis and systematic review using the best available evidence to assess the efficacy, efficiency, safety and patient satisfaction of double-balloon catheters in comparison with those of single-balloon devices among women who underwent labour induction with unfavourable cervixes.

\section{Methods}

\section{Search strategy}

Together with a clinical librarian (R.O.), an electronic literature search was conducted with the PubMed, EMBASE, OVID, SCI (via WOS), CENTRAL (The Cochrane Central Register of Controlled Trials) and ClinicalTrial.gov databases from inception through ebruary 14, 2018. The searching strategy was based on the PICOS principle, utilising medical subject headings and Boolean logic-based free-text combinations of the following search items: "labour induction", "cervical ripening", "balloon", "Foley", "Cook" and "Atad". In addition, we used sensitivity-maximising search filters to identify randomised controlled trials [24]. With the abovementioned databases, several meta-analyses and systematic reviews were identified. Aiming to identify more pertinent meta-analyses or systematic reviews, an additional search was performed in the CDSR (Cochrane Database of Systematic Reviews) database. All of the reference lists from the relevant reviews were manually retrieved to locate further eligible trials. There were no language restrictions. Differences of opinion were resolved by team discussion.

\section{Study selection and data collection}

All related RCTs that directly compared the doubleballoon catheter with the single-balloon catheter for the purposes of labour induction or cervical ripening were included in the analysis. There were no restrictions with regards to settings, demographics, obstetrics characteristics (e.g., race, maternal age, and gestational weeks) and outcome measures. We excluded the following types of studies: (1) studies of balloon catheters used for outpatient purposes; and (2) protocols, observational studies, and secondary analyses of previous studies and guidelines. Prior to the formal review process, we performed pretesting with the kappa statistic to calculate the level of agreement between the inclusion/exclusion decisions of different reviewers and adjusted our criterion until kappa $\geqq 0.75$.

To improve the precision of the collected data, two reviewers (X.Y.L., Y.W.), one who majored in obstetrics and one who did not, screened each record for eligibility and independently extracted and tabulated the following information from the text, tables, and graphs: lead author; publication year; country of origin; study design; participants and intervention characteristics; outcomes; and sponsor. Prior to determining the categories for the data collection forms, a pilot test was performed using representative samples of the studies to be reviewed. All of the collected data are available upon request.

Due to the uncertain benefits of blinded assessments and the large workload, we did not conceal the general contents of the studies during this process. Any disagreements were resolved through discussion, or if necessary, through consultation with a third reviewer (F.Z.) who specialises in evidence-based medicine. When information regarding any of the extracted data points listed above was unclear, an attempt was made to access further details by contacting the authors of the original reports.

\section{Selection of outcomes}

The primary and secondary outcomes were defined before trial retrieval was performed. The primary outcome was the caesarean delivery rate. The secondary outcomes included: (1) catheter placement (placement difficulty/ failure, spontaneous expulsion); (2) intervals (insertion to delivery, insertion to expulsion/removal, expulsion to delivery); (3) Bishop score increment; (4) vaginal delivery (vaginal delivery within $24 \mathrm{~h}$, normal vaginal delivery, assisted vaginal delivery); (5) analgesia usage; (6) maternal adverse events (death, infection, postpartum haemorrhage); (7) neonatal adverse events (death, low Apgar score, NICU admission); (8) length of hospitalisation; and (9) satisfaction (pain during the process, maternal total satisfaction). While we attempted to collect all of the above datapoints from all of the analysed studies, 
only those that provided all of the data appear in the analysis tables.

\section{Quality assessment}

Two independent investigators (X.Y.L., Y.W.) openly (not blinded) assessed the methodological quality of the included RCTs based on Cochrane risk-of-bias tool. Quality was graded based on the following criteria [25]: (1) high quality: both randomisation and allocation concealment were assessed as having low risks of bias, and all other items were assessed as having low or unclear levels of risk; (2) low quality: either randomisation or allocation concealment was assessed as having a high risk of bias, regardless of the risk levels of other items; and (3) moderate quality: trials did not meet the criteria for high or low quality. Discrepancies were resolved by consensus.

\section{Statistical analysis}

All statistical analyses were performed with RevMan version 5.3, with the help of a statistician (X.N.Z.). The relative risks (RRs) and mean differences (MDs), with corresponding 95\% confidence intervals (CIs), were used to describe the intervention effects for dichotomous and continuous variables, respectively. All potential data conversions utilised standard formulae recommended by the Cochrane Handbook [24].

Heterogeneity was identified by Cochrane's Q test and the $\mathrm{I}^{2}$-statistic test, in which a $\mathrm{Q}$ test $p$-value $<0.1$ and an $\mathrm{I}^{2}$ value $250 \%$ indicated significant heterogeneity. When both the $p$-value and the $\mathrm{I}^{2}$ value displayed no heterogeneity, we chose the fixed-effect model. Else, a random-effect model was used.

Subgroup analysis was pre-specified and performed on parity. A sensitivity analysis was conducted to identify studies involving data conversions that may have exerted a disproportionate influence on the pooled estimates. We assessed publication bias by examining funnel plots for the primary outcome only.

\section{Results}

\section{Study characteristics}

The literature search and screening process is shown in Fig. 1. Initially, 1326 potentially relevant records were identified. The titles and abstracts were reviewed, and 12 relevant trials were further screened. After thorough investigation, 7 RCTs, containing 1159 women and available data (577 and 582 in the double- and single-balloon groups, respectively), were determined to be eligible for inclusion [15-21]. The characteristics of the included trials are summarised in Table 1 . Table 2 shows the risk of bias and the corresponding quality of each individual trial, which is illustrated in Fig. 2a and b. Basic demographic and obstetric variables are presented in Table 3.
Except for postdates, which only two studies reported and which show slight heterogeneity, all other variables were comparable.

Of the 7 RCTs, 3 trials $[15,18,21]$ focused on nulliparous women, while 2 trials $[17,20]$ conducted subgroup analysis by parity. These 5 trials, which included 781 women (595 nulliparous and 186 multiparous), were suitable for parity subgroup analysis.

\section{Effects of interventions}

All trials reported the rates of caesarean section. There were no significant differences in the rates of caesarean delivery (RR, $0.88[0.65,1.2] ; p$-value, 0.43$)$ among trials, but heterogeneity existed (Q $p$-value, $0.04 ; \mathrm{I}^{2}, 55 \%$ ) (Fig. 3a). A corresponding funnel plot is shown in Fig. 3b. During sensitivity analysis, heterogeneity disappeared only when Salim 2011 [20] was excluded ( $\mathrm{Q} p$-value, $0.11 ; \mathrm{I}^{2}, 45 \%$ ), while the pooled effect was always robust (no significant differences). The secondary outcomes, shown in Table 4, did not differ obviously between the two types of catheter, except for the Bishop score increment (MD, 0.57 [0.28, 0.86]; $p$-value, 0.0001).

Subgroup analysis results by parity are shown in Tables 5 and Table 6. Only the Bishop score increment in nulliparous women exhibited a statistically significant difference; however, heterogeneity was demonstrated among studies (MD, 1.08 [0.38, 1.78]; Q $p$-value, $0.11 ; \mathrm{I}^{2}, 56 \% ; p$-value, 0.002$)$, suggesting that the double-balloon catheter may have a greater ability to increase the Bishop score. Unless otherwise highlighted, studies were homogeneous, and sensitivity analysis displayed no meaningful changes.

\section{Discussion}

\section{Summary of main results}

\section{Efficacy and efficiency}

Balloon catheters were initially designed for cervical dilatation and ripening during labour induction. The best indicator of efficacy is the Bishop score increment. However, when correlated with baseline data, the Bishop score served only as a secondary outcome. No significant differences were observed for obstetric characteristics (including the Bishop score before catheter insertion) between women treated with the single-balloon catheter and those treated with the double-balloon catheter. Therefore, we could use the Bishop score after catheter removal (the second Bishop score) to roughly calculate this effect size, and it was not necessary to perform covariance analyses to adjust the baseline data. According to our analysis, the double-balloon catheter increases the Bishop score more significantly, especially for nulliparous women. However, this result was not observed for the multiparous subgroup. In support of this finding, one study [17] reported a Bishop score $>6$ at balloon removal, and a similar trend in was observed for both 


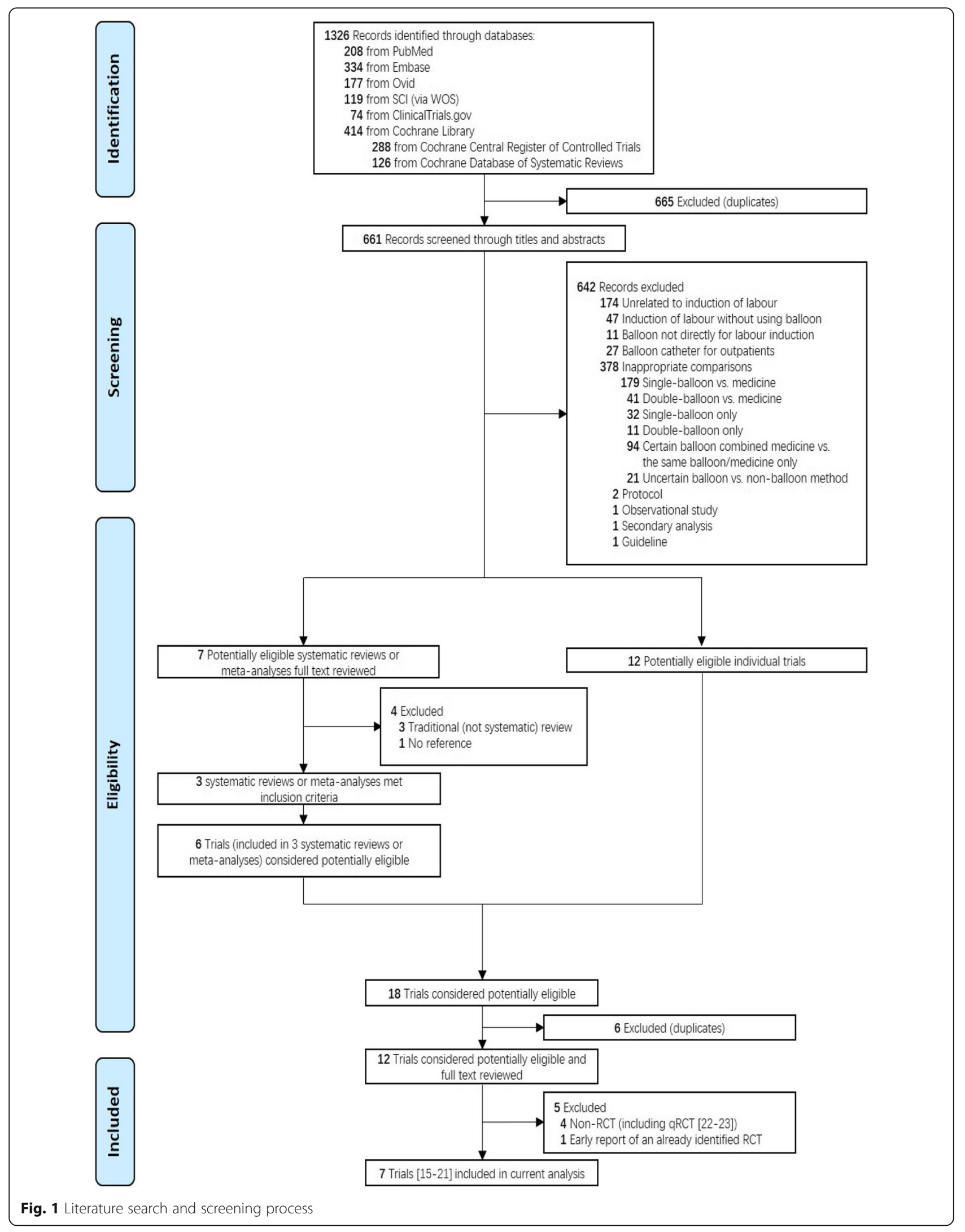


Table 1 Characteristics of the included trials

\begin{tabular}{|c|c|c|c|c|c|c|c|}
\hline \multirow[t]{2}{*}{ Study } & \multirow[t]{2}{*}{ Period } & \multirow[t]{2}{*}{ Country } & \multirow[t]{2}{*}{ Method } & \multirow{2}{*}{$\begin{array}{l}\text { Sample size } \\
\text { total } \\
\text { (double/ } \\
\text { single) }\end{array}$} & \multirow{2}{*}{$\begin{array}{l}\text { Parity total (double/ } \\
\text { single) }\end{array}$} & \multicolumn{2}{|c|}{ Balloon Catheter } \\
\hline & & & & & & Double $^{x}$ & Single \\
\hline Ahmed 2016 & 2013.03-2014.04 & Egypt & RCT & $78(39 / 39)$ & all nulliparous & Cook & Foley $(50 \mathrm{ml})$ \\
\hline Haugland 2012 & 2010.03-2011.01 & Norway & RCT & $178(88 / 90)$ & NA & Cook & Foley (NA) \\
\hline Hoppe 2015 & $2010.01-2013.11$ & USA & $\mathrm{RCT}$ & $98(50 / 48)$ & $\begin{array}{l}\text { nulliparous: } 50 \text { (25/25) } \\
\text { multiparous: } 48 \text { (25/23) }\end{array}$ & Cook & Foley $(30 \mathrm{ml})$ \\
\hline Pennell 2009* & 2001.07-2003.12 & Australia & RCT & $217(107 / 110)$ & all nulliparous & Atad & Foley $(30 \mathrm{ml})$ \\
\hline Rab 2015 & 2011.01-2013.12 & Egypt & $\mathrm{RCT}$ & $200(100 / 100)$ & $\begin{array}{l}\text { nulliparous: } 113 \text { (55/58) } \\
\text { multiparous: } 87 \text { (45/42) }\end{array}$ & Cook & Foley $(30 \mathrm{ml})$ \\
\hline Salim 2011 & 2008.06-2010.12 & Israel & RCT & $293(148 / 145)$ & $\begin{array}{l}\text { nulliparous: } 155 \text { (78/77) } \\
\text { multiparous: } 138 \text { (70/68) }\end{array}$ & Cook & Foley $(60 \mathrm{ml})$ \\
\hline Solt 2009 & $2006.01-2008.05$ & Israel & RCT & $95(45 / 50)^{\S}$ & $\begin{array}{l}\text { nulliparous: } 95(45 / 50) \\
\text { multiparous: } 85(\mathrm{NA})^{\S}\end{array}$ & Cook & Foley (NA) \\
\hline
\end{tabular}

Except for two studies $[16,21]$, in which we could not find detailed information, all studies offered similar standard instructions for how to use the balloon catheters

$\mathrm{x}$ : COOK/Atad: $80 \mathrm{ml}+80 \mathrm{ml}$, without tension

$y$ : All Foley catheters were applied with light tension

NA: Data not found: unable to contact the authors of the original reports

*: Pennell 2009 [18] was a multi-arm study, and we only extracted data for the double-balloon catheter and single-balloon catheter comparison arms

§: Solt 2009 [21] only reported the results of nulliparous women; therefore, we eliminated the multiparous subgroup and extracted nulliparous data only.

Table 2 Risk of bias and corresponding quality

\begin{tabular}{|c|c|c|c|c|c|c|c|c|}
\hline \multirow[t]{2}{*}{ Study } & \multicolumn{7}{|c|}{ Risk of bias for the included studies } & \multirow[t]{2}{*}{ Quality } \\
\hline & $\begin{array}{l}\text { Random sequence } \\
\text { generation } \\
\text { (selection bias) }\end{array}$ & $\begin{array}{l}\text { Allocation } \\
\text { concealment } \\
\text { (selection bias) }\end{array}$ & $\begin{array}{l}\text { Blinding of participants } \\
\text { and personnel } \\
\text { (performance bias) }^{x}\end{array}$ & $\begin{array}{l}\text { Blinding of } \\
\text { outcome } \\
\text { assessment } \\
\text { (detection bias) }\end{array}$ & $\begin{array}{l}\text { Incomplete } \\
\text { outcome data } \\
\text { (attrition bias) }\end{array}$ & $\begin{array}{l}\text { Selective } \\
\text { reporting } \\
\text { (reporting } \\
\text { bias) }^{y}\end{array}$ & $\begin{array}{l}\text { Other } \\
\text { bias }\end{array}$ & \\
\hline $\begin{array}{l}\text { Ahmed } \\
2016\end{array}$ & L & L & $U$ & $U$ & L & L & L & $\mathrm{H}$ \\
\hline $\begin{array}{l}\text { Haugland } \\
2012\end{array}$ & L & $U$ & L & L & L & L & $U$ & M \\
\hline $\begin{array}{l}\text { Hoppe } \\
2015^{A}\end{array}$ & L & L & $\mathrm{H}$ & $\mathrm{H}$ & L & L & L & M \\
\hline $\begin{array}{l}\text { Pennell } \\
2009\end{array}$ & L & L & $\mathrm{H}$ & L & L & L & L & $\mathrm{H}$ \\
\hline Rab 2014 & L & $U$ & $U$ & L & L & L & L & M \\
\hline $\begin{array}{l}\text { Salim } \\
2011^{A}\end{array}$ & L & L & $\mathrm{H}$ & $U$ & L & L & L & $\mathrm{H}$ \\
\hline Solt $2009^{B}$ & $\mathrm{~L}$ & L & $\mathrm{H}$ & L & L & $\mathrm{H}$ & $U$ & M \\
\hline
\end{tabular}

Other bias: trials sponsored by drug companies or trials in which baseline characteristics were not similar between different intervention groups

L: Low risk or low quality. For the risk of bias, $\mathrm{L}$ means appropriate methods were adequately described

$\mathrm{H}$ : High risk or high quality. For the risk of bias, $\mathrm{H}$ means high risk was found (unable to avoid bias)

U: Unclear risk, no description

M: Moderate quality

A: Hoppe et al. [17] and Salim et al. [20] reported a few lost follow-ups and did not perform intention-to-treat (ITT) analyses. Fortunately, they were balanced in numbers with similar reasons across intervention groups and had little influence on the following analysis. Therefore, we assessed the attrition bias as low B: Solt et al. [21] only described a single-blind method. Considering the nature of the study, we evaluated performance bias as $\mathrm{H}$, while detection bias was evaluated as L. Additionally, they selectively reported outcomes for the nulliparous group, and we could not obtain supplemental data for the multiparous group by contacting the author

$\mathrm{x}$ : Blinding of participants and personnel, though graded, was excluded from the quality assessment because it was impractical for these trials y: Some studies did not offer their protocols; therefore, it is difficult hard to determine whether the outcomes were not measured or not reported. Unless selective reporting was obvious, we evaluated this situation as being low risk 

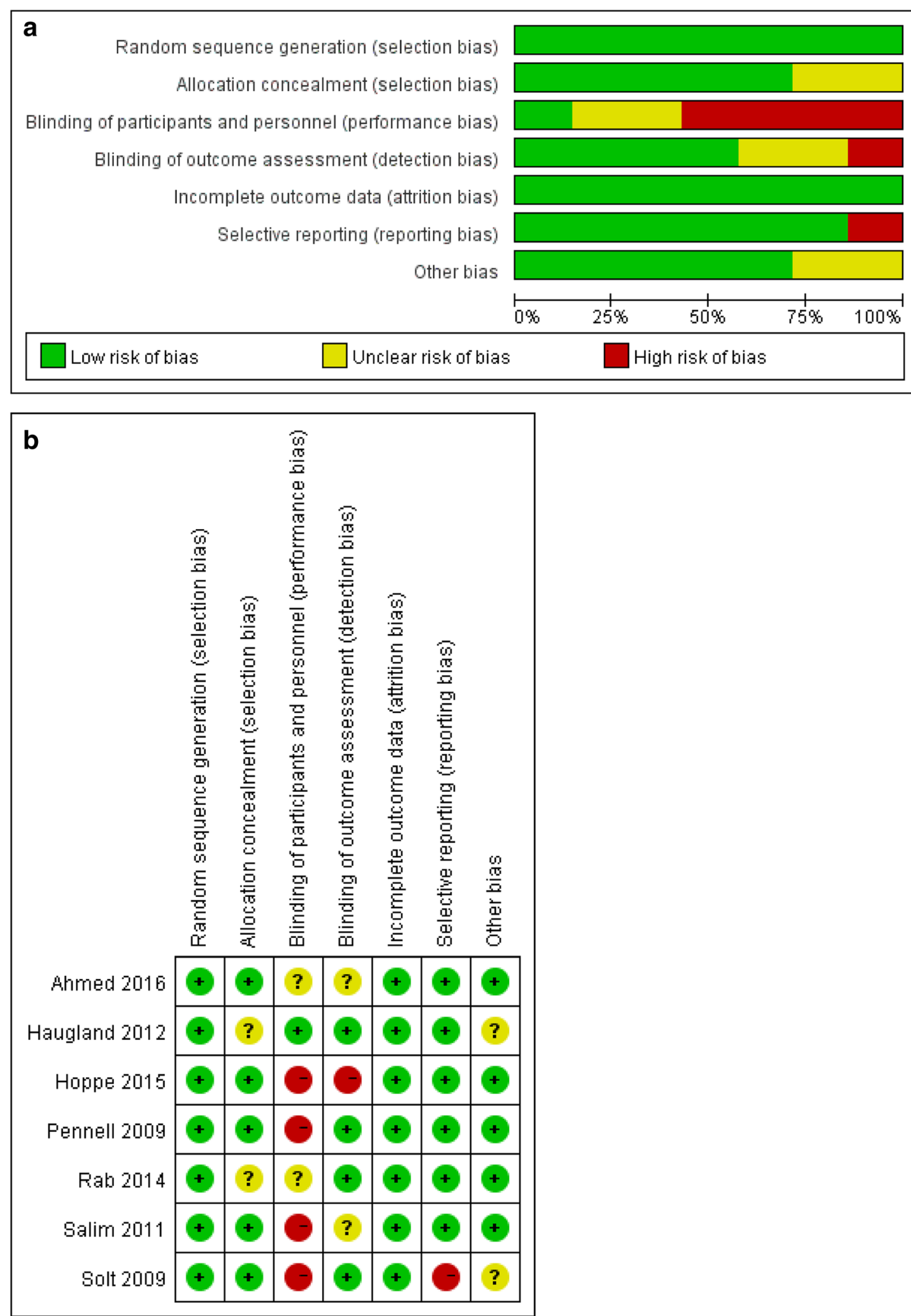

Fig. 2 a Risk of bias graph. b. Risk of bias summary 
Table 3 Basic demographic and obstetric variables

\begin{tabular}{|c|c|c|c|c|c|c|c|}
\hline \multirow[t]{2}{*}{ Variables* } & \multirow{2}{*}{$\begin{array}{l}\text { Number of } \\
\text { studies } \\
\text { analysed }\end{array}$} & \multicolumn{2}{|c|}{ Interventions } & \multirow{2}{*}{$\begin{array}{l}\text { Pooled effect } \\
(95 \% \mathrm{Cl})^{x}\end{array}$} & \multirow{2}{*}{$\begin{array}{l}\text { Q p- } \\
\text { value }^{y}\end{array}$} & \multirow{2}{*}{$\begin{array}{l}\mathrm{I}^{2}- \\
\text { statistic }^{y}\end{array}$} & \multirow{2}{*}{$\begin{array}{l}p- \\
\text { value }\end{array}$} \\
\hline & & Double & $\overline{\text { Single }}$ & & & & \\
\hline Maternal age (years) ${ }^{A}$ & $5[15,17-20]$ & 444 & 442 & $0.73[-0.08,1.53]$ & 0.89 & 0 & 0.08 \\
\hline Gestational weeks (weeks) ${ }^{\mathrm{A}}$ & $5[15,17-20]$ & 444 & 442 & $-0.07[-0.31,0.17]$ & 0.71 & 0 & 0.56 \\
\hline Bishop score at catheter insertion ${ }^{B}$ & $4[15,17,19-20]$ & 337 & 332 & $0.02[-0.19,0.23]$ & 0.42 & 0 & 0.85 \\
\hline \multicolumn{8}{|l|}{ Induction indications } \\
\hline Postdates ${ }^{c}$ & $2[17-18]$ & 157 & 158 & $1.10[0.51,2.37]$ & 0.15 & $51 \%$ & 0.81 \\
\hline Diabetes mellitus & $3[17-18,20]$ & 305 & 303 & $1.35[0.80,2.26]$ & 0.20 & $39 \%$ & 0.26 \\
\hline Hypertensive disease & $3[17-18,20]$ & 305 & 303 & $0.98[0.66,1.44]$ & 0.21 & $35 \%$ & 0.91 \\
\hline Intrauterine growth restriction & $2[17-18]$ & 157 & 158 & $0.92[0.39,2.21]$ & 0.23 & $29 \%$ & 0.86 \\
\hline
\end{tabular}

*: Only those variables contained in more than one study are displayed in this analysis table

Only Hoppe 2015 [17] described oligohydramnios and abnormal foetal monitoring and did not reveal significant differences

Rab 2014 [19] mentioned data on body mass index (BMI) at insertion, while Salim, 2011 [20] reported BMI data before pregnancy

Not all of the baseline data was described in Haugland, 2012 [16] and Solt, 2009 [21]

A: Pennell 2009 [18] described the maternal age and gestational weeks by median and typical range. The results remained the same after sensitivity analysis

B: Pennell 2009 [18] described the Bishop score using ordinal data, making synthesis impossible

C: Postdates, as one of the induction indications, shows heterogeneity between the two studies $[17,18]$

$x$ : The odds ratio (OR) was the pooled effect for dichotomous variables. The mean difference (MD) was the pooled effect for continuous outcomes

y: Study heterogeneity was explored using Cochrane's Q test and the $I^{2}$-statistic test. Random- and fixed-effect models were used as appropriate

$z$ : The $p$-value $\geq 0.05$ for the test indicated that the pooled effect was insignificant; for dichotomous outcomes, the test was OR $=1$; for continuous outcomes, the test was $M D=0$

general and subgroup subjects. Additionally, the ripening success rates (defined by the individual articles) appeared to be higher in the double-balloon groups, but without enough statistical power to determine significance $[16,19,22,23]$. Atad et al. also reported similarly large average increments in the Bishop scores for both nulliparous and multiparous women for the doubleballoon catheter, without a single-balloon catheter comparison group [11]. Later, the researchers reported that the Bishop score increment when employing the singleballoon catheter was lower than that achieved by the double-balloon catheter, with a higher failure rate [26].

Efficiency, best evaluated by the interval length and the $24 \mathrm{~h}$ delivery rate, is comparable regardless of parity. In the double-balloon catheter group, the interval from insertion to delivery appears to be longer, while the interval from expulsion to delivery appears to be shorter, though neither measure achieves significance. Ahmed, et al. [15] stated that women treated with a singleballoon catheter had a shorter insertion to amniotomy time $(p=0.02)$ than women treated with a doubleballoon catheter, while Pennell, et al. [18] found that the length of labour did not significantly differ $(p=0.152)$ between the two groups; there is little consensus on the time from insertion to active labour, with Pennell, et al. [18] preferring the single-balloon catheter $(p=0.014)$, while Rab, et al., [19] demonstrated no obvious differences. Ahmed and Mei-Dan [15, 22] suggested that the shorter interval between insertion and expulsion for the single-balloon catheter likely resulted in the observed shorter induction to delivery interval, although the second Bishop score was lower in this group.
The frequency of placement difficulty or failure and spontaneous expulsion are similar between the two groups. In addition, Salim, et al. [20] found that women who spontaneously expelled their catheter demonstrated favourable outcomes with regards to shorter times from induction to delivery (1.10 [1.06-1.15]; $p=0.001)$ and a significantly lower proportion of operative deliveries (2.15 [1.26-3.69]; $p=0.003)$.

\section{Safety}

Both maternal and neonatal adverse events are of great concern. Although we hoped to consider mortality data, no study provided this information. Other measurements were also equivalent, including maternal infection, postpartum haemorrhage, low Apgar scores and NICU admissions. Some studies also $[18,20]$ reported placental abruptions, uterine hyperstimulation, cord prolapse, malpresentation, and Apgar $<4$ at 1 min, with no significant differences between groups.

\section{Satisfaction}

Patient-reported outcomes (PROs), such as maternal satisfaction, represent what is most important to patients about a condition and its treatment [24]. However, few reports related to PROs were found. Here, we can report patient satisfaction based on two original reports [15, 19], both evaluated by the visual analogue scale (VAS) [27], with identical measurement times and protocols. The pooled results of these two studies suggests similar satisfaction levels for the two catheter types. 


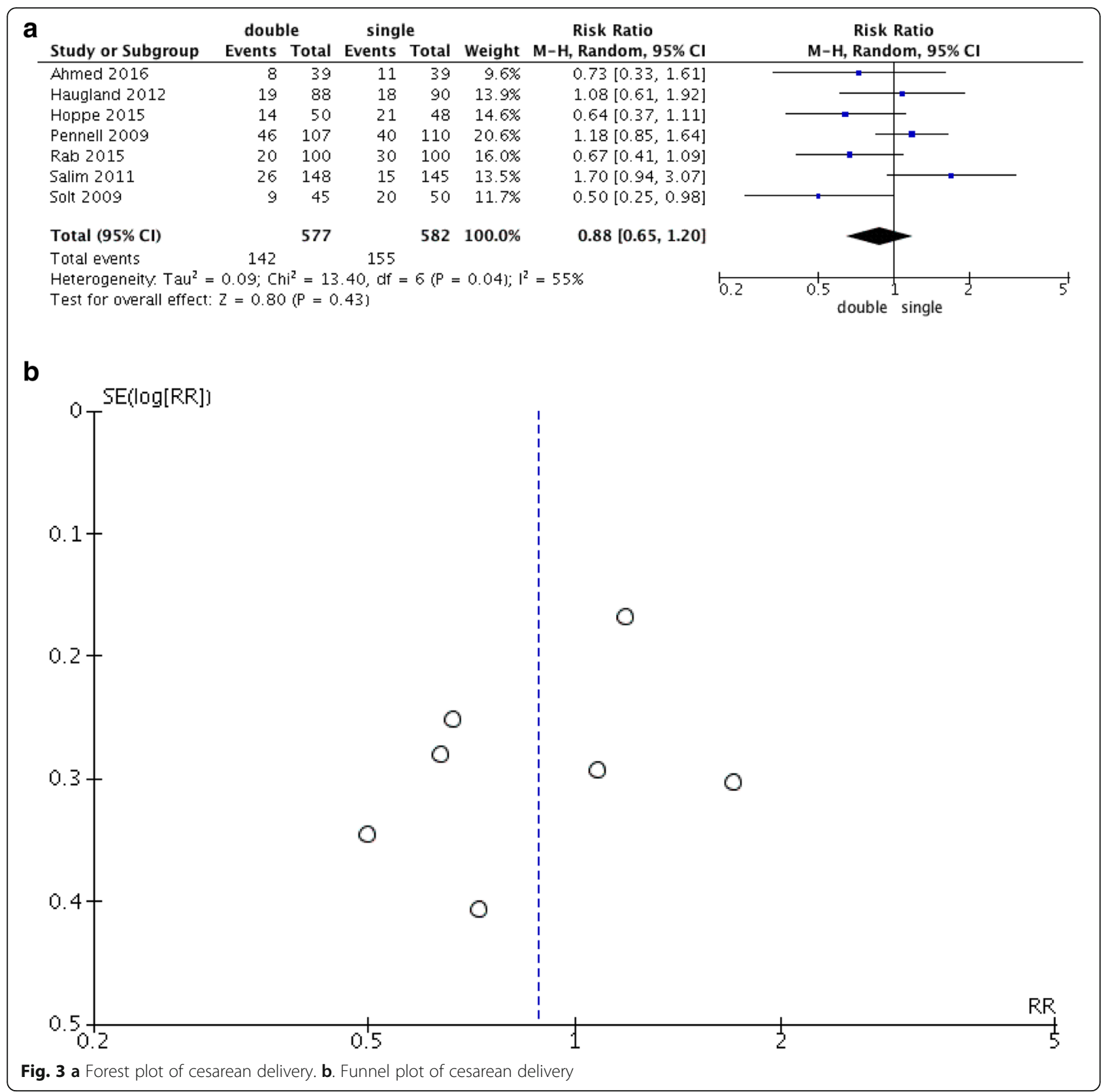

\section{Comprehensive outcomes}

Delivery modes, which are of particular clinical concern, represent a comprehensive measurement of the effectiveness and safety of labour induction protocols and can incorporate economic evidence. Caesarean section delivery is the most frequently used outcome pre-specified by trials. According to our analysis, no strong evidence exists to demonstrate which mechanical device is more effective, and heterogeneity exists among studies. Similarly, both normal and assisted vaginal delivery rates were comparable between groups, regardless of parity, as were the rates of analgesia usage during the ripening process and the lengths of hospitalisation.

\section{Heterogeneity}

Heterogeneity exists in many results, which may be the result of differences in study design or quality, participants, interventions, demographic feature or local policies. During our heterogeneity test, three studies $[17,19,20]$ were potential candidates for being the sources of heterogeneity. Unlike other studies, Rab et al. [19] enrolled women who had experienced a stillbirth and had scarred uteri, which could be responsible increasing the general heterogeneity. Additional differences among these studies involved parity and balloon volumes (discussed below). 
Table 4 Secondary outcomes

\begin{tabular}{|c|c|c|c|c|c|c|c|c|c|}
\hline \multirow[t]{2}{*}{ Outcomes } & \multirow{2}{*}{$\begin{array}{l}\text { Number of } \\
\text { studies } \\
\text { analysed }\end{array}$} & \multicolumn{2}{|c|}{ Interventions } & \multirow{2}{*}{$\begin{array}{l}\text { Effect } \\
\text { measure }\end{array}$} & \multirow{2}{*}{$\begin{array}{l}\text { Pooled effect } \\
(95 \% \text { Cl) }\end{array}$} & \multirow[t]{2}{*}{ Q p-value } & \multirow{2}{*}{$\begin{array}{l}\mathrm{I}^{2} \text { - } \\
\text { statistic }\end{array}$} & \multirow{2}{*}{$\begin{array}{l}p- \\
\text { value }\end{array}$} & \multirow{2}{*}{$\begin{array}{l}\text { Sensitivity } \\
\text { analysis }\end{array}$} \\
\hline & & Double & Single & & & & & & \\
\hline placement difficulty/failure & $4[15-16,18,20]$ & 382 & 384 & RR & $1.34[0.66,2.71]$ & 0.55 & 0 & 0.42 & stable \\
\hline spontaneous expulsion & $4[15,17,19-20]$ & 337 & 332 & RR & $0.86[0.60,1.23]$ & 0.0002 & $85 \%$ & 0.40 & stable \\
\hline \multirow[t]{2}{*}{ insertion to delivery interval $^{A}$} & \multirow[t]{2}{*}{$6[15-20]$} & \multirow[t]{2}{*}{532} & \multirow[t]{2}{*}{532} & \multirow[t]{2}{*}{ MD } & $0.98[-0.03,2.00]$ & 0.16 & $36 \%$ & 0.06 & Unstable \\
\hline & & & & & $1.36[-0.63,3.34]$ & 0.02 & $61 \%$ & 0.18 & Unstable" \\
\hline insertion to expulsion/removal interval ${ }^{B}$ & $4[15,17,19-20]$ & 278 & 267 & MD & $1.72[-0.35,3.79]$ & $<0.00001$ & $93 \%$ & 0.10 & Unstable!II \\
\hline expulsion to delivery interval & $2[19,21]$ & 145 & 150 & MD & $-2.81[-10.82,5.19]$ & 0.06 & $72 \%$ & 0.49 & - \\
\hline Bishop score increment ${ }^{c}$ & $5[15,17,19-21]$ & 382 & 382 & MD & $0.57[0.28,0.86]$ & 0.30 & $18 \%$ & 0.0001 & stable \\
\hline vaginal delivery within $24 \mathrm{~h}$ & $3[17-18,20]$ & 305 & 303 & RR & $0.95[0.72,1.26]$ & 0.11 & $54 \%$ & 0.74 & Unstable $^{\mathrm{IV}}$ \\
\hline normal vaginal delivery ${ }^{\mathrm{D}}$ & 6 [15-20] & 532 & 532 & $\mathrm{RR}$ & $1.02[0.86,1.20]$ & 0.03 & $59 \%$ & 0.84 & Unstable $^{V}$ \\
\hline assisted vaginal delivery ${ }^{\mathrm{D}}$ & $4[16,18-20]$ & 443 & 445 & $\mathrm{RR}$ & $1.08[0.84,1.41]$ & 0.48 & 0 & 0.54 & stable \\
\hline analgesia usage & $4[17-20]$ & 405 & 403 & RR & $1.07[0.99,1.16]$ & 0.72 & 0 & 0.10 & stable \\
\hline \multicolumn{10}{|l|}{ maternal adverse events } \\
\hline maternal infection & $5[17-21]$ & 450 & 453 & RR & $1.04[0.66,1.66]$ & 0.38 & $5 \%$ & 0.85 & stable \\
\hline postpartum haemorrhage & $3[15,18-19]$ & 246 & 249 & $\mathrm{RR}$ & $1.03[0.74,1.42]$ & 0.73 & 0 & 0.88 & stable \\
\hline \multicolumn{10}{|l|}{ neonatal adverse events } \\
\hline low Apgar score $(<7 \text { at } 5 \mathrm{~min})^{\mathrm{E}}$ & $3[17-18,20]$ & 305 & 303 & RR & $0.53[0.15,1.88]$ & 0.46 & 0 & 0.32 & - \\
\hline NICU admission & $3[17-18,20]$ & 305 & 303 & RR & $0.70[0.45,1.07$ & 0.90 & 0 & 0.10 & stable \\
\hline length of hospitalisation & 2 [19-20] & 248 & 245 & MD & $0.16[-0.10,0.41]$ & 0.28 & $15 \%$ & 0.22 & - \\
\hline \multicolumn{10}{|l|}{ satisfaction ${ }^{F}$} \\
\hline pain during the process & $2[15,19]$ & 139 & 139 & MD & $0.07[-0.53,0.67]$ & 0.42 & 0 & 0.82 & - \\
\hline maternal total satisfaction & $2[15,19]$ & 139 & 139 & MD & $-0.10[-1.25,1.04]$ & 0.08 & $68 \%$ & 0.86 & - \\
\hline
\end{tabular}

A: No studies, except for those of Hoppe 2015 [17] and Salim 2011 [20], specifically defined delivery as being either total delivery or vaginal delivery. Hoppe 2015 [17] offered data on the time from insertion to vaginal delivery, while Salim 2011 [20] reported both measurements. We synthesised these data by involving Hoppe 2015 [17]. The upper and lower data shows the effects when we added the total and vaginal delivery data from Salim 2011 [20]

B: Salim 2011 [20] excluded 124 women (70 in the double-balloon catheter group and 54 in the single-balloon catheter group) with spontaneous expulsion during this process

C: We depended primarily on the Bishop score increment. For those studies that included only a second Bishop score, we included these data and conducted sensitivity analyses

D: Hoppe 2015 [17] reported only vaginal deliveries but did not define whether assisted vaginal deliveries were included; we treated these data as though it did not include assisted vaginal deliveries

E: Salim 2011 [20] reported no events on this outcome for either arm, which was inestimable

F: All measured by VAS

I: When we eliminated Salim 2011 [20], the MD pooled effect changed to 2.16 [0.76, 3.57] ( $p$-value, 0.003), in favour of the single-balloon catheter. The results remained comparable after all other sensitivity analyses were performed

II: Excluding Rab 2014 [19], though heterogeneity disappeared, the effect remained comparable (Q $p$-value, 0.17; ${ }^{2}, 38 \% ; p$-value, 0.58). Excluding Salim 2011 [20], the result was shown in superscript note I

III: Significant heterogeneity existed regardless of which study we excluded; however, when we repeated the analysis after excluding Salim 2011 [20], the result changed (MD, 2.40 [0.32, 4.48]; supporting the single-balloon catheter)

IV: Stable effect but became homogeneous only when we excluded Hoppe 2015 [17]

V: Stable effect but became homogeneous only when we excluded Rab 2014 [19] or Salim, 2011 [20]

\section{Applicability of evidence \\ Guide clinical Practice}

Despite the fact that the double-balloon makes results in more favourable Bishop scores, it appears to result in prolonged intervals. No differences were observed for delivery mode, which is the most meaningful obstetrical outcome. As for the economical consideration, it is mainly related to hospitalization length, delivery mode and device itself. What is noteworthy is that the single balloon (Foley catheter) is approximately 30-40 times cheaper than the double-balloon catheter at different institutions, and the difference of price varies from countries to countries. As the producers offered that Foley catheters cost approximately $\$ 1.12$, while Cook catheters cost approximately \$39.33. As for our hospital in China, the single balloon catheter costs 20-30 RMB while the double one costs $600 \mathrm{RMB}$, and the price for placing balloon catheters is about $600 \mathrm{RMB}$ in both situations. Considering the fact that caesarean section and hospitalization length were similar in the two groups, and when coupled with a substantial price differences in the devices, the single balloon catheter seems like to be 
Table 5 Outcomes by parity (nulliparous)

\begin{tabular}{|c|c|c|c|c|c|c|c|c|c|}
\hline \multirow[t]{2}{*}{ Outcomes* } & \multirow{2}{*}{$\begin{array}{l}\text { Number of } \\
\text { studies analysed }\end{array}$} & \multicolumn{2}{|c|}{ Interventions } & \multirow{2}{*}{$\begin{array}{l}\text { Effect } \\
\text { measure }\end{array}$} & \multirow{2}{*}{$\begin{array}{l}\text { Pooled effect } \\
(95 \% \text { Cl) }\end{array}$} & \multirow{2}{*}{$\begin{array}{l}\text { Q p- } \\
\text { value }\end{array}$} & \multirow{2}{*}{$\begin{array}{l}\mathrm{I}^{2}- \\
\text { statistic }\end{array}$} & \multirow{2}{*}{$\begin{array}{l}p- \\
\text { value }\end{array}$} & \multirow{2}{*}{$\begin{array}{l}\text { Sensitivity } \\
\text { analysis }\end{array}$} \\
\hline & & Double & $\overline{\text { Single }}$ & & & & & & \\
\hline caesarean delivery & $5[15,17-18,20-21]$ & 294 & 301 & RR & $0.86[0.56,1.33]$ & 0.02 & $65 \%$ & 0.50 & stable \\
\hline placement difficulty/failure & $2[15,18]$ & 146 & 149 & $\mathrm{RR}$ & $0.72[0.15,3.55]$ & 0.57 & 0 & 0.69 & - \\
\hline spontaneous expulsion & $1[15]$ & 39 & 39 & RR & $0.88[0.70,1.10]$ & - & - & 0.27 & - \\
\hline \multirow[t]{2}{*}{ insertion to delivery interval ${ }^{\mathrm{A}}$} & \multirow[t]{2}{*}{$4[15,17-18,20]$} & \multirow[t]{2}{*}{249} & \multirow[t]{2}{*}{251} & \multirow[t]{2}{*}{ MD } & $0.88[-0.43,2.18]$ & 0.59 & 0 & 0.19 & stable \\
\hline & & & & & $0.43[-0.84,1.71]$ & 0.26 & $26 \%$ & 0.50 & stable \\
\hline insertion to expulsion/removal interval & $2[15,17]$ & 64 & 64 & MD & $0.88[-0.00,1.76]$ & 0.38 & 0 & 0.05 & - \\
\hline expulsion to delivery interval & $1[21]$ & 45 & 50 & MD & $-8.00[-16.35,0.35]$ & - & - & 0.06 & - \\
\hline Bishop score increment ${ }^{c}$ & $3[15,17,21]$ & 109 & 114 & MD & $1.08[0.38,1.78]$ & 0.11 & $56 \%$ & 0.002 & Unstable ${ }^{\prime}$ \\
\hline vaginal delivery within $24 \mathrm{~h}$ & $3[17-18,20]$ & 210 & 212 & $\mathrm{RR}$ & $0.91[0.75,1.10]$ & 0.19 & $40 \%$ & 0.33 & stable \\
\hline normal vaginal delivery ${ }^{\mathrm{D}}$ & $4[15,17-18,20]$ & 249 & 251 & $\mathrm{RR}$ & $1.00[0.78,1.29]$ & 0.17 & $58 \%$ & 0.98 & Unstable" \\
\hline assisted vaginal delivery ${ }^{\mathrm{D}}$ & $2[18,20]$ & 185 & 187 & RR & $1.02[0.65,1.59]$ & 0.56 & 0 & 0.94 & - \\
\hline analgesia usage & $2[18,20]$ & 185 & 187 & $\mathrm{RR}$ & $1.06[0.95,1.19]$ & 0.32 & $1 \%$ & 0.28 & - \\
\hline \multicolumn{10}{|l|}{ maternal adverse events } \\
\hline maternal infection & $3[18,20-21]$ & 230 & 237 & $\mathrm{RR}$ & $1.16[0.69,1.95]$ & 0.27 & $24 \%$ & 0.58 & stable \\
\hline postpartum haemorrhage & $2[15,18]$ & 146 & 149 & $\mathrm{RR}$ & $1.00[0.72,1.40]$ & 0.49 & 0 & 0.98 & - \\
\hline \multicolumn{10}{|l|}{ neonatal adverse events } \\
\hline low Apgar score $(<7 \text { at } 5 \mathrm{~min})^{\mathrm{E}}$ & $2[18,20]$ & 185 & 187 & RR & $0.21[0.01,4.23]$ & - & - & 0.31 & - \\
\hline NICU admission & $1[18]$ & 107 & 110 & $\mathrm{RR}$ & $0.74[0.45,1.22]$ & - & - & 0.24 & - \\
\hline \multicolumn{10}{|l|}{ satisfaction $^{F}$} \\
\hline pain during the process & $1[15]$ & 39 & 39 & MD & $-0.40[-1.69,0.89]$ & - & - & 0.54 & - \\
\hline maternal total satisfaction & $1[15]$ & 39 & 39 & MD & $0.47[-0.42,1.36]$ & - & - & 0.30 & - \\
\hline
\end{tabular}

* Superscript notes (A-F) are the same as those for Table 4

I: Excluding Hoppe 2015 [17], although heterogeneity disappeared, the effect remained (Q $p$-value, 0.46; $I^{2}, 0 ; p$-value, 0.002). Excluding Solt 2009 [21], heterogeneity still existed, but the effect significance disappeared (Q $p$-value, $0.03 ; I^{2}, 78 \%$; $p$-value, 0.07$)$

II: Results remained comparable, but heterogeneity disappeared after we excluded Hoppe 2015 [17] (Q $p$-value, 0.27; $I^{2}, 24 \% ; p$-value, 0.21)

Table 6 Outcomes by parity (multiparous)

\begin{tabular}{|c|c|c|c|c|c|c|c|c|c|}
\hline \multirow[t]{2}{*}{ Outcomes* } & \multirow{2}{*}{$\begin{array}{l}\text { Number } \\
\text { of } \\
\text { studies } \\
\text { analysed }\end{array}$} & \multicolumn{2}{|c|}{ Interventions } & \multirow{2}{*}{$\begin{array}{l}\text { Effect } \\
\text { measure }\end{array}$} & \multirow{2}{*}{$\begin{array}{l}\text { Pooled effect } \\
(95 \% \mathrm{Cl})\end{array}$} & \multirow{2}{*}{$\begin{array}{l}\text { Q p- } \\
\text { value }\end{array}$} & \multirow{2}{*}{$\begin{array}{l}\mathrm{I}^{2} \text { - } \\
\text { statistic }\end{array}$} & \multirow{2}{*}{$\begin{array}{l}p \text { - } \\
\text { value }\end{array}$} & \multirow{2}{*}{$\begin{array}{l}\text { Sensitivity } \\
\text { analysis }\end{array}$} \\
\hline & & Double & Single & & & & & & \\
\hline caesarean delivery & $2[17,20]$ & 95 & 91 & $\mathrm{RR}$ & $1.35[0.54,3.36]$ & 0.43 & 0 & 0.52 & - \\
\hline \multirow[t]{2}{*}{ insertion to delivery interval ${ }^{\mathrm{A}}$} & \multirow[t]{2}{*}{$2[17,20]$} & \multirow[t]{2}{*}{95} & \multirow[t]{2}{*}{91} & \multirow[t]{2}{*}{ MD } & $-0.48[-2.24,1.28]$ & 0.62 & 0 & 0.60 & - \\
\hline & & & & & $-1.05[-2.68,0.58]$ & 0.70 & 0 & 0.21 & - \\
\hline insertion to expulsion/removal interval & $1[17]$ & 25 & 23 & MD & $2.30[-0.97,5.57]$ & - & - & 0.17 & - \\
\hline Bishop score increment ${ }^{C}$ & $1[17]$ & 25 & 23 & MD & $0.20[-0.88,1.28]$ & - & - & 0.72 & - \\
\hline vaginal delivery within $24 \mathrm{~h}$ & $2[17,20]$ & 95 & 91 & RR & $1.05[0.93,1.18]$ & 0.21 & $36 \%$ & 0.46 & - \\
\hline normal vaginal delivery ${ }^{\mathrm{D}}$ & $2[17,20]$ & 95 & 91 & RR & $0.92[0.83,1.02]$ & 0.36 & 0 & 0.13 & - \\
\hline assisted vaginal delivery ${ }^{\mathrm{D}}$ & $1[20]$ & 70 & 68 & RR & $8.75[0.48,159.42]$ & - & - & 0.14 & - \\
\hline analgesia usage & $1[20]$ & 70 & 68 & RR & $1.20[0.70,2.07]$ & - & - & 0.51 & - \\
\hline maternal adverse events (infection) & $1[20]$ & 70 & 68 & RR & $2.92[0.12,70.35]$ & - & - & 0.51 & - \\
\hline neonatal adverse events (low Apgar score) ${ }^{\mathrm{E}}$ & $1[20]$ & 70 & 68 & $\mathrm{RR}$ & Not estimable & - & - & - & - \\
\hline
\end{tabular}


more cost-effective for labour induction, particularly in low resource settings.

\section{Exploring the mechanisms}

Practically, in our hospital, we prefer to place a balloon catheter at night, avoiding expulsion due to daily activity. Thus far, no studies have focused on this issue as a potential mechanism for labour induction. Theoretically, the insertion of a foreign object could increase the risk of intrauterine infections; however, the limited data from our analysis and previous studies did not show any evidence that the cervical ripening balloon catheter contributes to increased infection occurrences $[6,18,20,22$, 28-31]. More studies are required to address the effects of the balloon-catheters on the rupturing of membranes and infection. In addition, physiologic differences in the mechanism through which balloon catheters induce labour according to parity also must be assessed.

Prior research demonstrated that a Bishop score $>5$ was associated with a greater likelihood of vaginal delivery [32, 33]. Although a higher Bishop score was achieved in the double-balloon group in our analysis, there were no differences in the vaginal delivery rates between the two groups. This result interested us, and we hypothesise that there may exist a threshold for the Bishop score that, once achieved, no further effects will be generated; after this threshold is met, the level of hormone secretions takes precedence over cervical conditions. Similar what is observed in our practice, favourable outcomes are rarely observed with balloon usage alone, unless augmentations (e.g., prostaglandin or oxytocin) are utilised.

The larger volume, the application of pressure on two sides (harder expulsion), and the ability to abandon traction when using the double-balloon catheter may explain the observed outcomes. The larger volume balloon may increase the separation between the amniotic membranes and the uterine decidua, resulting in an increase in the local secretion of prostaglandins and enhancing the cervical ripening process. Though $60 \mathrm{ml}$ and $80 \mathrm{ml}$ Foley catheters are more effective than $30 \mathrm{ml}$ catheters [34-36], $80 \mathrm{ml}+80 \mathrm{ml}$ Atad or COOK balloons do not demonstrate superiority to smaller Foley catheters, which may be due to other factors (e.g., traction). We hypothesise that traction may have a greater effect on the induction of labour and that the one-sided application of pressure may interfere with the labour pattern less than two-sided pressure. In theory, traction may cause discomfort for patients. However, this finding has not been confirmed by our analysis. Instead, speculum application prior to catheter insertion, which followed the same procedure in both groups, appears to be the main source of discomfort [15].

Further studies are required to investigate the possible biological mechanisms on cervical ripening and the sources of discomfort, to provide practice guidelines and instrument improvement.

\section{Identifying the optimal methods for various populations}

Although there were no restrictions on settings, demographics or obstetrics characteristics, the participants from all of the included studies, except for Rab [19], were women with viable singletons and without scarred uteri, making the applicability of our evidence limited. Vaginal birth after caesarean delivery (VBAC) has received increasing attention [37], but identifying the optimal method for labour induction in this specific population remains controversial. Pharmacological methods are often rejected in VBAC women because of greater risks of complications. However, whether balloon catheters can and should be utilised in women with scarred uteri, which manufacturers do not recommend, requires further studies. In addition, twins and other multiple pregnancies are contraindications for the use of balloon catheters, despite the increased frequency of multiple pregnancies. Whether balloon catheters can be used in situations with multiple pregnancies also deserves further study.

\section{Strengths and limitations}

In the current meta-analysis, no demographic or obstetric characteristics were restricted, which increases the applicability of the evidence. We performed evaluations examining evidence of bias and applied quality grades strictly based on the original reports and the Cochrane handbook. The 7 included trials are all rigorous in design, enabling the appraisal and interpretation of their results. Additionally, because bias is more important for studies with subjective events and positive results than for studies with negative results and objective outcomes, such as our analysis, it was acceptable to assume that bias would not practically undermine the results of our analysis.

When extracting data, some outcomes with various forms required data conversions, which likely led to analytical bias. Although we conducted sensitivity analysis specifically to test this possibility, it cannot be clearly determined whether these conversions influenced our outcomes. In addition, the outcomes we chose for this analysis are widely used in practice to avoid potential inconsistencies, and appropriate subgroup analyses were performed to identify potential sources of heterogeneity; however, heterogeneity remained too comprehensive to analyse fully.

The sample size of the current analysis had adequate power for the evaluation of the primary outcome. For some secondary outcomes, fewer data points were available, which may result in insufficient power and higher risks of publication bias. To minimise this bias and to 
involve more relevant studies, we have done our best to search databases using a wide range of publication years, to consider potentially eligible reviews and to fully utilise trial registration databases, with sensitivity-maximising search filters. Unfortunately, we are still incapable of accessing conference abstracts or proceedings and grey literature. Thus, publication bias cannot be excluded completely, and caution should be taken.

The procedures performed during our analysis to reduce bias and assess risks can provide direction for further research, although not all of these are necessary.

\section{Conclusions}

Both kinds of balloon catheter perform similarly with regards to efficacy, efficiency, safety and patient satisfaction. The single-balloon device appears to be more economical and practical, particularly in low resource settings.

\section{Abbreviations}

CCRB: Cook Cervical Ripening Balloon; CDSR: Cochrane Database of Systematic Reviews; CENTRAL: Cochrane Central Register of Controlled Trials; Cls: Confidence intervals; MDs: Mean differences; PICOS: Population, intervention, comparison, outcomes and study designs; PROs: Patientreported outcomes; RCTs: Randomised controlled trials; RRs: Relative risks; USFDA: United States Food and Drug Administration; VAS: Visual analogue scale; VBAC: Vaginal birth after caesarean delivery

\section{Acknowledgements}

Not applicable.

\section{Authors' contributions}

$H B Q, X L$ and $X Y L$ contributed to the protocol design. The literature search was conducted by $X Y L$ and $Y W$, with the help of RO. Study screening and data extraction were independently performed by XYL and YW. FZ contributed to resolving disagreements during these processes. All statistical analyses were completed with the aid of XNZ. XYL and YW reviewed and prepared the manuscript. $\mathrm{HBQ}$ and $\mathrm{XL}$ are guarantors of this manuscript. All authors have read and approved the final version of the manuscript.

\section{Funding}

The National Natural Science Foundation of China (No. 81771614 and No. 81771613)

The National Key Research and Development Program of China (No.2016YFC1000407).

The funders had no involvement in the study design, data collection and analysis, interpretation of data and preparation of the manuscript.

\section{Availability of data and materials}

All data generated or analysed during the current study are available from the corresponding author on reasonable request.

\section{Ethics approval and consent to participate}

Not applicable.

\section{Consent for publication}

Not applicable.

\section{Competing interests}

We declare that none of the authors have any financial relationships or personal relationships with people, pharmaceutical companies or other commercial entities that have an interest in the subject matter or materials discussed in the article.

\section{Author details}

${ }^{1}$ Department of Obstetrics and Gynecology, The First Affiliated Hospital of Chongqing Medical University, No. 1 Youyi Road, Yuzhong District,
Chongqing 400016, China. ${ }^{2}$ First Clinical Institute, Chongqing Medical University, No. 1 Yixueyuan Road, Yuzhong District, Chongqing 400016 China. ${ }^{3}$ School of Public Health and Management, Chongqing Medical University, No. 1 Yixueyuan Road, Yuzhong District, Chongqing 400016, China.

Received: 25 July 2018 Accepted: 4 September 2019

Published online: 16 October 2019

\section{References}

1. Managing complications in pregnancy and childbirth: a guide for midwives and doctors. Second edition. Geneva Switzerland Who 2017. http://reprolineplus.org/ system/files/resources/mcpc_guide_eng.pdf. Accessed 02 Jan 2018.

2. Bishop EH. Pelvic scoring for elective induction. Obstet Gynecol. 1964;24:266-8.

3. DA W: Induction of labour (electronic version). In: Lockwood CJ, editor. UpToDate 2018 [www.uptodate.com] Accessed 02 Jan 2018

4. Riskin-Mashiah S, ., Wilkins I, . Cervical ripening. Obstet Gynecol Clin N Am 1999, 26(2):243-257.

5. Cocks DP. Significance of initial condition of cervix uteri to subsequent course of labour. Br Med J. 1955;1(4909):327.

6. Jozwiak M, Bloemenkamp KW, Kelly AJ, Mol BW, Irion O, Boulvain M. Mechanical methods for induction of labour. Cochrane Database Syst Rev. (2012, 3):CD001233.

7. ACOG Practice Bulletin No. 107: induction of labor. Obstet Gynecol 2009, 114(2 Pt 1):386-397.

8. Thiery MBC, MJNC K. The development of methods for inducing labour. In: Chalmers I, Enkin MW, MJNC K, editors. Effective care in pregnancy and childbirth, vol. 1989. Oxford: Oxford University Press; 1989. p. 971.

9. WHO Recommendations for Induction of Labour. edn. Geneva; 2011.

10. Embrey MP, Mollison BG. The unfavourable cervix and induction of labour using a cervical balloon. J Obstet Gynaecol Br Commonw. 1967;74(1):44-8.

11. Atad J, Bornstein J, Calderon I, Petrikovsky BM, Sorokin Y, Abramovici H. Nonpharmaceutical ripening of the unfavorable cervix and induction of labor by a novel double balloon device. Obstet Gynecol. 1991;77(1):146-52.

12. Cook Medical, Cervical Ripening Balloon Instructions for Use. https://www. cookmedical.com/data/IFU_PDF/T_J-CCRB_REV2.PDF. Accessed 02 Jan 2018.

13. Keirse MJ, Thiery M, Parewijck W, Mitchell MD. Chronic stimulation of uterine prostaglandin synthesis during cervical ripening before the onset of labor. Prostaglandins. 1983;25(5):671-82.

14. Krammer J, O'Brien WF. Mechanical methods of cervical ripening. Clin Obstet Gynecol. 1995;38(2):280-6.

15. Sayed Ahmed WA, Ibrahim ZM, Ashor OE, Mohamed ML, Ahmed MR, Elshahat AM. Use of the Foley catheter versus a double balloon cervical ripening catheter in pre-induction cervical ripening in postdate primigravidae. J Obstet Gynaecol Res. 2016:42(11):1489-94.

16. Haugland B, Albrechtsen S, Lamark E, Rasmussen S, Kessler J. Induction of labor with single- versus double-balloon catheter - a randomized controlled trial. Acta Obstet Gynecol Scand. 2012;91:85

17. Hoppe KK, Schiff MA, Peterson SE, Gravett MG. $30 \mathrm{~mL}$ single- versus $80 \mathrm{~mL}$ double-balloon catheter for pre-induction cervical ripening: a randomized controlled trial. J Matern Fetal Neonatal Med. 2016;29(12):1919-25.

18. Pennell CE, Henderson JJ, O'Neill MJ, McChlery S, Doherty DA, Dickinson JE. Induction of labour in nulliparous women with an unfavourable cervix: a randomised controlled trial comparing double and single balloon catheters and PGE2 gel. BJOG. 2009;116(11):1443-52.

19. Rab MT, Mohammed AB, Zahran KA, Hassan MM, Eldeen AR, Ebrahim EM, Yehia M. Transcervical Foley's catheter versus Cook balloon for cervical ripening in stillbirth with a scarred uterus: a randomized controlled trial. J Matern Fetal Neonatal Med. 2015;28(10):1181-5.

20. Salim R, Zafran N, Nachum Z, Garmi G, Kraiem N, Shalev E. Single-balloon compared with double-balloon catheters for induction of labor: a randomized controlled trial. Obstet Gynecol. 2011;118(1):79-86.

21. Solt I, Ben-Harush S, Kaminsky S, Sosnovsky V, Ophir E, Bornstein J. A prospective randomized study comparing induction of labor with the Foley catheter and the cervical ripening double balloon catheter in nuliparous and multiparous women. Am J Obstetr Gynecol. 2009;201(6):S124.

22. Mei-Dan E, Walfisch A, Suarez-Easton S, Hallak M. Comparison of two mechanical devices for cervical ripening: a prospective quasi-randomized trial. J Matern Fetal Neonatal Med. 2012;25(6):723-7.

23. Mei-Dan E, Walfisch A, Valencia C, Hallak M. Making cervical ripening EASI: a prospective controlled comparison of single versus double balloon catheters. J Matern Fetal Neonatal Med. 2014;27(17):1765-70. 
24. Higgins J, Green S: Cochrane handbook for systematic reviews of interventions version 5.1.0. http://handbook-5-1.cochrane.org/. [updated march 2011]: Wiley-Blackwell; 2011.

25. Zhao JG, Zeng XT, Wang J, Liu L. Association between calcium or vitamin D supplementation and fracture incidence in community-dwelling older adults: a systematic review and meta-analysis. JAMA. 2017;318(24):2466-82.

26. Atad J, Hallak M, Ben-David Y, Auslender R, Abramovici H. Ripening and dilatation of the unfavourable cervix for induction of labour by a double balloon device: experience with 250 cases. Br J Obstet Gynaecol. 1997; 104(1):29-32.

27. Aitken RC. Measurement of feelings using visual analogue scales. Proc R Soc Med. 1969;62(10):989-93

28. Sciscione AC, Bedder CL, Hoffman MK, Ruhstaller K, Shlossman PA. The timing of adverse events with Foley catheter preinduction cervical ripening; implications for outpatient use. Am J Perinatol. 2014;31(9):781-6.

29. Jagielska I, Kazdepka-Zieminska A, Janicki R, Formaniak J, Walentowicz Sadlecka M, Grabiec M. Evaluation of the efficacy and safety of Foley catheter pre-induction of labor. Ginekol Pol. 2013;84(3):180-5.

30. Sciscione AC, Muench M, Pollock M, Jenkins TM, Tildon-Burton J, Colmorgen GH. Transcervical Foley catheter for preinduction cervical ripening in an outpatient versus inpatient setting. Obstet Gynecol. 2001;98(5 Pt 1):751-6.

31. Sciscione A, Larkin M, O'Shea A, Pollock M, Hoffman M, Colmorgen G. Preinduction cervical ripening with the Foley catheter and the risk of subsequent preterm birth. Am J Obstet Gynecol. 2004:190(3):751-4.

32. Nielsen PE, Howard BC, Crabtree T, Batig AL, Pates JA. The distribution and predictive value of Bishop scores in nulliparas between 37 and 42 weeks gestation. J Matern Fetal Neonatal Med. 2012;25(3):281-5.

33. Johnson DP, Davis NR, Brown AJ. Risk of cesarean delivery after induction at term in nulliparous women with an unfavorable cervix. Am J Obstet Gynecol. 2003;188(6):1565-9 discussion 1569-1572.

34. Delaney S, Shaffer BL, Cheng YW, Vargas J, Sparks TN, Paul K, Caughey AB. Labor induction with a Foley balloon inflated to $30 \mathrm{~mL}$ compared with 60 $\mathrm{mL}$ : a randomized controlled trial. Obstet Gynecol. 2010;115(6):1239-45.

35. Levy R, Kanengiser B, Furman B, Ben Arie A, Brown D, Hagay ZJ. A randomized trial comparing a 30-mL and an 80-mL Foley catheter balloon for preinduction cervical ripening. Am J Obstet Gynecol. 2004;191(5):1632-6.

36. Kashanian M, Nazemi M, Malakzadegan A. Comparison of 30-mL and 80-mL Foley catheter balloons and oxytocin for preinduction cervical ripening. Int J Gynaecol Obstet. 2009;105(2):174-5.

37. Practice Bulletin No. 184 Summary: Vaginal birth after cesarean delivery. Obstet Gynecol 2017, 130(5):1167-1169.

\section{Publisher's Note}

Springer Nature remains neutral with regard to jurisdictional claims in published maps and institutional affiliations.

Ready to submit your research? Choose BMC and benefit from:

- fast, convenient online submission

- thorough peer review by experienced researchers in your field

- rapid publication on acceptance

- support for research data, including large and complex data types

- gold Open Access which fosters wider collaboration and increased citations

- maximum visibility for your research: over $100 \mathrm{M}$ website views per year

At $\mathrm{BMC}$, research is always in progress.

Learn more biomedcentral.com/submissions 